KLEINE TEXTE FƯR VORLESUNGEN UND ÚBUNGEN HERAUSGEGEBEN VON HANS LIETZMANN

148

\title{
DIE DEUTSCHEN LIEDER \\ DER \\ CARMINA BURANA
}

NACH DER HANDSCHRIFT CLM 4660 DER STAATSBIBLIOTHEK MÜNCHEN

HERAUSGEGEBEN VON

DR. FRIEDRICH LÜERS

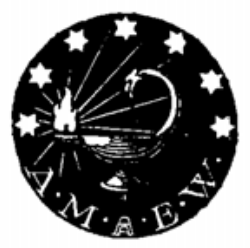

BONN

A. MARCUS UND E. WEBER'S VERLAG 1922 
MEINER LIEBEN FRAU GABRIELE

ZUM 9. SEPTEMBER 1922

GEWIDMET 